\section{REFERENCES}

1. Stillwell F. Globalisation: where do we go from here? NSW Public Health Bulletin 2001; 12(7): 183-185.

2. Deaton A. Policy implications of the gradient of health and wealth. Health Affairs March-April 2002; 21(2), www.130.94.25.113/freecontents/s6.htm (15 March 2002).

3. Dahlgren G, Whitehead M. Tackling inequalities: a review of policy initiatives. Tackling Inequalities in Health. An Agenda for Action. Benzeval M, Judge K, Whitehead M (editors). London: King's Fund, 1995; 22-52.
4. Najman JM. A general model of the social origins of health and wellbeing. The Social Origins of Health and Wellbeing. Eckersley R, Dixon J, Douglas B (editors). Melbourne: Cambridge University Press, 2001.

5. Turrell G, Mathers CD. Socioeconomic status and health in Australia. Med J Aust 2000; 172: 434-438.

6. Wise M. Taking responsibility to address inequalities in health. NSW Public Health Bulletin 2001; 12(7): 186-189.

\title{
WHAT IF NEW SOUTH WALES WAS MORE EQUAL?
}

\section{Kevin McCracken \\ Department of Human Geography \\ Macquarie University}

In the international health status 'league tables', Australia ranks among the best in the world. For example, on the measure of healthy life expectancy (that is, disabilityadjusted life expectancy), the World Health Report 2000 rated Australia second out of 191 countries. ${ }^{1}$ However, as Sainsbury and Harris remind us in the guest editorial to the first issue in the health inequalities series of the NSW Public Health Bulletin (Volume 12, Number 5): 'there are substantial inequalities in health in NSW and Australia' and 'these inequalities translate into large differences in levels of mortality and morbidity'. ${ }^{2}$

This article describes an estimate of the excess mortality burden in NSW and focuses on the following questions: What if NSW was more equal? Each year, how many premature deaths might be prevented if we could remove all inequalities in our society?

Clearly, there is no unequivocal or precise answer to these two questions, as the answer depends on how 'excess' mortality is identified and measured. Despite the elusiveness of any definitive answer, the questions are worth posing because they remind us of the scope that still remains for reducing premature mortality across New South Wales.

\section{BACKGROUND—APPROACHESTO MEASURING EXCESS MORTALITY}

The notion of excess (or avoidable, unnecessary, and preventable) mortality has a lengthy history, dating back at least to the mid-nineteenth century in the work of the English statistician, William Farr. ${ }^{3}$ Concerted research interest in the topic, however, is more recent, developing over the past three decades or so.
Two basic types of methodologies have been employed to estimate excess mortality. The first type of methodology has been based on identifying causes of death that supposedly can be prevented in various ways. Work in this methodology derives from a compilation of a list of 'unnecessary untimely deaths' (that is, 'sentinel health events') by a working group on preventable and manageable diseases in the United States. ${ }^{4}$ Subsequent researchers have used and extended this list in studies of avoidable mortality in a wide variety of geographic settings. ${ }^{5-10}$ Early work in this methodology tended to focus on mortality from conditions amenable to medical intervention (that is, secondary and tertiary prevention), but some of the more recent studies have extended the concept of avoidability to cover primary prevention (that is, reducing the incidence of the condition through individual behavioural change and population level interventions). ${ }^{11,12}$

The second type of methodology has been based on the idea of selecting a favourable level of mortality as a standard and then defining excess deaths as those above that reference level. This, in fact, was the approach taken by Farr in the nineteenth century. ${ }^{3}$ Farr noted that, in districts in England with the most favourable sanitary conditions, the crude death rate did not exceed 17 per 1000 population; and, accordingly, he adopted this rate as representing 'natural' deaths. Any deaths above this rate were deemed to be 'unnatural'. Several variants of this 'best mortality' criterion have been used by modern researchers. One strategy has been to use the age-specific and sex-specific mortality prevailing in the highest social class as a benchmark. ${ }^{13,14}$ Another has been to assemble the lowest age-specific and sex-specific death rates recorded in selected geographic units as a benchmark. ${ }^{15-17}$ An interesting recent British study, meanwhile, has placed 
the 'best mortality' approach in a government policy framework, by estimating the effect on death rates if life in Britain was changed through three successful government policy initiatives: the achievement of full employment, the eradication of child poverty, and a modest redistribution of income. ${ }^{18}$

\section{METHODS AND DATA}

For the analyses reported here, the 'best mortality' approach has been employed. Two geographic areas are used as 'best mortality' reference benchmarks, the Northern Sydney Area Health Service (NSAHS) and the Ku-ringgai Local Government Area (KLGA). The NSAHS has the lowest age-standardised mortality rates for both males and females of the State's 17 area health services, ${ }^{19}$ while the KLGA-which is located within the NSAHS - has the lowest age-standardised and sex-standardised premature mortality ratio of any large (that is, $>100,000$ resident population) local government area within NSW. ${ }^{20}$ These 'best mortality' positions have been consistently held by both geographic units for many years.

Unpublished deaths tabulations by age (in five-year groups), and by sex and cause, for the years 1995-1997 (combined) for NSW local government areas were purchased from the Australian Bureau of Statistics. Average annual age-specific and sex-specific death rates for the NSAHS (Model A) and KLGA (Model B) were calculated from these data and from 1996 estimated resident population (ERP) figures. These rates were then applied to NSW's ERP and the ERPs of each of the State's area health services to calculate the number of deaths the
State as a whole (and each area health service) would have experienced if they had had the age-specific and sexspecific death rates of the reference populations.

Excess mortality was defined as the difference between the actual number of deaths experienced and the expected number, and excess deaths were expressed as a percentage of actual deaths to give an index of proportional excess mortality (PEMI). The procedure is thus simply indirect standardisation, but with selected 'best mortality' agespecific and sex-specific rates used as the standard, rather than the normal practice, in NSW Department of Health publications, of using rates for NSW as the benchmark.

To dampen the influence of random fluctuations in the data, three years of mortality statistics combined were used. To this end, one run of the NSAHS-based calculations of excess mortality (Model C) was conducted using the area's specific rates adjusted up to the upper limit of their respective 95 per cent confidence intervals to give a more conservative estimate of avoidable deaths. A similarly-adjusted KLGA model (Model D) was also run.

The consideration of excess mortality was confined to deaths under 75 years of age. This is not to deny the occurrence and importance of avoidable deaths at higher ages. However, deaths before age 75 can be thought of as premature and thus of particular concern. Most of the previous work on excess (avoidable) mortality has used an upper age limit of 64 years; but, in recognition of improvements in life expectancy, the higher limit was chosen here.

\section{TABLE 1}

NUMBER OF LIVES POTENTIALLY 'SAVED', AND OBSERVED DEATHS, NSW*, 1995-1997

\begin{tabular}{|c|c|c|c|c|c|c|c|c|c|c|}
\hline & \multicolumn{8}{|c|}{ Number of lives potentially 'saved' per year } & \multicolumn{2}{|c|}{ Observed Deaths } \\
\hline & \multicolumn{2}{|c|}{$\begin{array}{c}\text { Model A } \\
\text { (NSAHS rates } \\
\text { unadjusted) }\end{array}$} & \multicolumn{2}{|c|}{$\begin{array}{l}\text { Model B } \\
\text { (KLGA rates } \\
\text { unadjusted) }\end{array}$} & \multicolumn{2}{|c|}{$\begin{array}{c}\text { Model C } \\
\text { (NSAHS rates }^{\text {adjusted) }}{ }^{* *}\end{array}$} & \multicolumn{2}{|c|}{$\begin{array}{c}\text { Model D } \\
\text { (KLGA rates } \\
\text { adjusted) }{ }^{* *}\end{array}$} & \multicolumn{2}{|c|}{$\begin{array}{c}\text { New South Wales } \\
\text { Average Annual } \\
\text { Deaths 1995-1997 }\end{array}$} \\
\hline \multicolumn{11}{|l|}{ Age } \\
\hline Group & Males & Females & Males & Females & Males & Females & Males & Females & Males & Females \\
\hline $0-14$ & 115 & 33 & 202 & 58 & 34 & 0 & 30 & 58 & 407 & 318 \\
\hline $15-34$ & 383 & 112 & 231 & 230 & 213 & 19 & 0 & 133 & 1098 & 373 \\
\hline $35-54$ & 720 & 311 & 1123 & 399 & 478 & 126 & 616 & 94 & 2199 & 1250 \\
\hline $55-64$ & 881 & 219 & 1097 & 465 & 689 & 92 & 641 & 90 & 2682 & 1534 \\
\hline $65-74$ & 1387 & 599 & 2787 & 1048 & 1067 & 349 & 2107 & 443 & 6137 & 3753 \\
\hline Total & 3486 & 1274 & 5440 & 2200 & 2481 & 586 & 3394 & 818 & 12523 & 7228 \\
\hline \multicolumn{11}{|c|}{$\begin{array}{l}\text { * Based on New South Wales' estimated resident population at } 30 \text { June } 1996 . \\
\text { ** For some age groups the confidence interval adjustment made the NSAHS and KLGA rates higher than the NSW } \\
\text { ones. In such cases the number of lives potentially saveable was taken as zero. }\end{array}$} \\
\hline
\end{tabular}




\section{TABLE 2}

PROPORTIONAL EXCESS MORTALITY INDEX, IN PERCENTAGES, NSW*, 1995-1997

\begin{tabular}{|c|c|c|c|c|c|c|c|c|}
\hline \multirow{2}{*}{ Age } & \multicolumn{2}{|c|}{$\begin{array}{c}\text { Model A } \\
\text { (NSAHS rates } \\
\text { unadjusted) }\end{array}$} & \multicolumn{2}{|c|}{$\begin{array}{c}\text { Model B } \\
\text { (KLGA rates } \\
\text { unadjusted) }\end{array}$} & \multicolumn{2}{|c|}{$\begin{array}{c}\text { Model C } \\
\text { (NSAHS rates } \\
\text { adjusted)** }\end{array}$} & \multicolumn{2}{|c|}{$\begin{array}{c}\text { Model D } \\
\text { (KLGA rates } \\
\text { adjusted) }{ }^{\star *}\end{array}$} \\
\hline & & & & & & & & \\
\hline Group & Males & Females & Males & Females & Males & Females & Males & Females \\
\hline $0-14$ & 28 & 10 & 50 & 18 & 8 & 0 & 7 & 18 \\
\hline $15-34$ & 35 & 30 & 21 & 62 & 19 & 5 & 0 & 36 \\
\hline $35-54$ & 33 & 25 & 51 & 32 & 22 & 10 & 28 & 8 \\
\hline $55-64$ & 33 & 14 & 41 & 30 & 26 & 6 & 24 & 6 \\
\hline $65-74$ & 23 & 16 & 45 & 28 & 17 & 9 & 34 & 12 \\
\hline Total & 28 & 18 & 43 & 30 & 20 & 8 & 27 & 11 \\
\hline
\end{tabular}

* Based on New South Wales' estimated resident population at 30 June 1996.

** For some age groups the confidence interval adjustment made the NSAHS and KLGA rates higher than the NSW ones. In such cases the number of lives potentially saveable was taken as zero.

\section{TABLE 3}

PREVENTABLE MORTALITY BY AREA HEALTH SERVICE, NSW*, 1995-1997

\begin{tabular}{lccccc}
\hline Area health service & $\begin{array}{c}\text { Lives potentially } \\
\text { 'saved' }\end{array}$ & $\begin{array}{c}\text { PEMI } \\
(\%)\end{array}$ & Area health service & $\begin{array}{c}\text { Lives potentially } \\
\text { 'saved' }\end{array}$ & $\begin{array}{c}\text { PEMI } \\
\text { (\%) }\end{array}$ \\
\hline Central Sydney & 486 & 30 & Northern Rivers & 211 & 23 \\
Northern Sydney & 0 & 0 & Mid North Coast & 210 & 21 \\
South Eastern Sydney & 369 & 17 & New England & 219 & 34 \\
South Western Sydney & 511 & 25 & Macquarie & 142 & 37 \\
Western Sydney & 489 & 27 & Mid Western & 122 & 33 \\
Wentworth & 190 & 25 & Far West & 291 \\
Central Coast & 289 & 27 & Greater Murray & 194 & 31 \\
Hunter & 514 & 28 & Southern & $\mathbf{4 7 6 0}$ \\
IIlawarra & 304 & 25 & NSW Total & $\mathbf{2 4}$ \\
\hline Note: The area health service lives that could have been 'saved' do not sum to the NSW total as area health \\
service of residence details were not available for a small number of recorded deaths. \\
Based on New South Wales' estimated resident population at 30 June 1996.
\end{tabular}

\section{RESULTS}

\section{All-causes mortality in NSW}

Table 1 summarises the annual excess death toll for the State under the four models. Using the unadjusted NSAHS and KLGA age-specific and sex-specific rates, Models A and $\mathrm{B}$, produce excess mortality figures of 4760 and 7640 people respectively. On the other hand, the more conservative confidence interval-adjusted NSAHS rates (Model C) gives a total of 3067, while the adjusted KLGA rates (Model D) yield an excess of 4212. The proportion of total actual deaths (males and females combined) identified as excess varies from 24 per cent (Model A), to 39 per cent (Model B), to 16 per cent (Model C) to 21 per cent (Model D).
In all four models, males dominate the excess figures, with a sex ratio ranging from $4.2: 1$ in the adjusted NSAHS model to $2.5: 1$ in the unadjusted KLGA model. The age group in which excess deaths are proportionately strongest varies among models (Table 2), though in absolute terms in each case the greatest number of such deaths is in the 65-74 year bracket.

\section{All-causes mortality by area health services}

Estimates of excess mortality in each of the area health services are given in Table 3. Only the unadjusted NSAHS rates (that is, Model A) were employed for these calculations. These figures give each area health authority a simple quantitative indication of the 'saveable lives' 


\section{TABLE 4}

PREVENTABLE MORTALITY FROM SELECTED CAUSE OF DEATH, NSW*, 1995-1997

\begin{tabular}{|c|c|c|c|}
\hline $\begin{array}{l}\text { Cause of Death } \\
\text { ICD9 Code }\end{array}$ & Name & $\begin{array}{l}\text { Lives potentially } \\
\text { 'saved' }\end{array}$ & $\begin{array}{l}\text { PEMI } \\
(\%)\end{array}$ \\
\hline $153-154$ & Colorectal cancer & 101 & 11 \\
\hline 162 & Lung cancer & 531 & 35 \\
\hline $410-414$ & Ischaemic heart disease & 1113 & 30 \\
\hline $430-438$ & Cerebrovascular disease & 219 & 20 \\
\hline $460-519$ & Respiratory diseases & 575 & 41 \\
\hline E800-E949 & Accidents & 388 & 37 \\
\hline E810-E819 & Motor vehicle accidents & 210 & 41 \\
\hline E950-E959 & Suicide & 121 & 16 \\
\hline 001-999 & All causes & 4760 & 24 \\
\hline
\end{tabular}

(per the chosen algorithm) within its bounds, with the NSAHS - by definition as the benchmark-having zero. They of course, though, reflect the population size as well as mortality level of each area health service, and so the proportional excess mortality index (PEMI) also needs to be considered. By this measure, the Far West Area has the highest degree of excess mortality in the State, just under half of total deaths in that area rating as such. The Macquarie Area (37 per cent) and the New England Area (34 per cent) have the next highest indexes.

\section{Causes of death in NSW}

The overall NSW results, disaggregated by leading causes of death, are presented in Table 4. Again only Model A (that is, NSAHS rates unadjusted) was used for these calculations. By this estimation, ischaemic heart disease offers the greatest absolute potential for 'saving' lives (1113 people), followed by respiratory diseases and lung cancer. Proportionally, respiratory diseases (41 per cent) and motor vehicle accident (41 per cent) deaths have the largest excess component. For some causes of death other area health services have lower rates than the NSAHS, and thus different cause-specific results would obviously be obtained if those areas were used as the standard.

\section{DISCUSSION}

The results reported above clearly show the scope that still remains for reducing premature mortality in NSW, despite a very favourable level of life expectancy overall. Employing the 'best mortality' approach is a useful variation from the norm in the NSW Department of Health publications of using the overall State rates of mortality as the comparative benchmark. Taking the State level as the benchmark usefully identifies areas with above average mortality and need for special attention, but carries the risk of glossing over the potential for still further improvement in areas with better than average rates. The more rigorous best mortality criterion is a reminder of this potential.

Obviously, the assumption that all areas can achieve agespecific and sex-specific mortality rates as low as those in the 'best mortality' area does not completely hold. The higher mortality of some areas, for example, may reflect above average proportions of people exposed to determinants of health not amenable to prevention: for instance, genetic predisposition to certain diseases. However, the bulk of the inequality in mortality among population subgroups in NSW, and thorughout Australia as a whole, is socially and behaviourally determined; and thus, at least theoretically, is open to improvement.

To return to the opening question of how many people in NSW each year go to unnecessarily early graves, the author's view is that the unadjusted NSAHS rates model (Model A) offers a reasonable working figure; that is, close to 5000 persons under the age of 75 . The confidence interval adjustment (Models $\mathrm{C}$ and D) was introduced into the analysis in recognition of the fact that mortality rates comprise both random and systematic variation. That adjustment naturally reduced the identified excess toll. However, examination of area health service all-causes mortality patterns through the 1990s shows that:

(a) the NSAHS to have consistently had the lowest male and female rates;

(b) the relative mortality standing of the 17 area health services to have been very stable.

The correlation between the areas' 1990-1994 and 19941998 age-standardised and sex-standardised all-causes rates was $r=0.98$. Hence the support for the unadjusted NSAHS model.

It might well be argued, though, that the feasible reduceable excess toll is even higher, as the unadjusted 
KLGA model (Model B) suggests. While, theoretically, the smaller population and number of deaths involved makes those rates more sensitive to random fluctuation, the KLGA, like the overall NSAHS of which it is part, has a consistent record of very favourable mortality and thus might be considered a proven achievable target level. Adopting the KLGA as the benchmark also has the benefit of identifying the scope for improvement that remains even within the area health service with the 'best mortality'. In turn, within the KLGA itself there are still deaths occurring that are avoidable.

\section{REFERENCES}

1. World Health Organization. Health Systems: Improving Performance. The World Health Report 2000. Geneva: WHO, 2000.

2. Sainsbury P, Harris E. Health inequalities: something old, something new. NSW Public Health Bulletin 2001; 12(5): $117-9$.

3. Farr W. Vital Statistics: A Memorial Volume of Selections and Writings. Humphreys NA (editor). London: E. Stanford, 1885.

4. Rutstein DD, Berenberg W, Chalmers TC, et al. Measuring the quality of medical care-A clinical method. $N$ Engl J Med 1976; 294: 582-8.

5. Charlton JRH, Hartley RM, Silver R, Holland WW. Geographical variation in mortality from conditions amenable to medical intervention in England and Wales. Lancet 1983; i: 691-6.

6. Charlton JRH, Velez, R. Some international comparisons of mortality amenable to medical intervention. BMJ 1986; 292 : 295-301.

7. Holland WW (editor). European Community Atlas of 'Avoidable Death'. Oxford: Oxford University Press, 1988.

8. Mackenbach JP, Kunst AE, Looman CWN, et al. Regional differences in mortality from conditions amenable to medical intervention in The Netherlands: a comparison of four time periods. J Epidemiol Community Health 1988; 42: 325-32.

9. Marshall RJ, Keating GM. Area variation of avoidable causes of death in Auckland, 1977-85. N Z Med J 1989; 102: 464-5.

10. Wood E, Sallar AM, Schechter MT, Hogg RS. Social inequalities in male mortality amenable to medical intervention in British Columbia. Soc Sci Med 1999; 48: 1751-8.

11. Simonato L, Ballard T, Bellini P, Winkelmann R. Avoidable mortality in Europe 1955-1994: A plea for prevention. $J$ Epidemiol Community Health 1998; 52: 624-30.

12. Tobias M, Jackson G. Avoidable mortality in New Zealand, 1981-97. Aust N Z J Public Health 2001; 25: 12-20.

13. Department of Health and Social Security. Inequalities in Health: Report of a Research Working Group. London: DHSS, 1980.

14. Mathers C, Vos T, Stevenson C. The Burden of Disease and Injury in Australia. Australian Institute of Health and Welfare Catalogue no. PHE 17. Canberra: AIHW, 1999.

15. Guralnick L, Jackson A. An index of unnecessary deaths. Public Health Reports 1967; 82: 180-2.

16. Woolsey T. Toward an Index of Preventable Mortality. US Department of Health and Human Services Publication no. (PHS) 81-1359 (Vital and Health Statistics, Series 2, No. 85), Hyattsville, Md: DHSS, 1981.

17. Uemura, K. Excess mortality ratio with reference to the lowest age-sex-specific death rates among countries. World Health Statistics Quarterly 1989; 42: 26-41.

18. Mitchell R, Dorling D, and Shaw M. Inequalities in Life and Death: What if Britain Were More Equal? Bristol: The Policy Press, 2000.

19. Public Health Division. The Health of the People of New South Wales-Report of the Chief Health Officer, 2000. Sydney: NSW Department of Health, 2000.

20. Glover J, Tennant S. A Social Health Atlas of Australia (2nd edition.). Volume 2.1: New South Wales. Adelaide: Public Health Information Development Unit, University of Adelaide, 1999. 